\title{
Comparisons of Hybrid Multi-Objective Programming Algorithms with Grey Target and PCA for Weapon System Portfolio Selection
}

\author{
Yajie Dou*, Pengle Zhang, Jiang Jiang, Kewei Yang and Yingwu Chen \\ College of Information System and Management, National University of Defense Technology, Changsha, Hunan, 410073, P. R. China
}

Received: 27 Jun. 2013, Revised: 1 Nov. 2013, Accepted: 2 Nov. 2013

Published online: 1 May. 2014

\begin{abstract}
Weapon Systems Portfolio Selection (WSPS) can be considered as a multi-objective decision analysis (MODA) problem. Aiming at its challenging features because of, 1) interactions and independencies among weapon systems, 2) the uncertainty of the sample data set for assessment, and 3) the missing target value of the assessment criteria, the WSPS problem is solved form four perspectives: portfolio without the independencies or target value, portfolio with the independencies but without target value, portfolio with the independencies and target value, portfolio in a incomplete sample data with the independencies and with target value. The synergy concept is introduced to describe the independencies among systems and Grey Target (GT) and principal component analysis (PCA) method are employed in this study to deal with the missing target value and incomplete sample data set. Three hybrid multiobjective programming algorithms are proposed as GT-MOP1, GT-MOP2 and PCA-MOP2 and non-dominated portfolios are generated as by sorting algorithm as a set of Pareto-optimal solutions. Finally, numerical experiments are given under four scenarios to illustrate the feasibilities and advantages of the three hybrid algorithms.
\end{abstract}

Keywords: Weapon system portfolio selection (WSPS), multi-objective programming (MOP), grey target (GT), principal component analysis (PCA)

\section{Introduction}

Weapon Systems Portfolio Selection (WSPS) is directly and tightly correlated with national military force development. Especially for the future battle spaces, it is meaningful and useful to deliver an integrated operational force which performs effectively and avoids increasing technical risks in defense industry. In the past twenty years of research on military portfolio selection, the most common analysis techniques include multiple objective analysis $[1,2,3,4,5,6,7,8,9,12]$, multiple criteria analysis [10], value analysis $[4,5,6,7,8,9]$, optimization $[6,7,8,9$, $10,11]$, cost-efficiency analysis $[9,10]$ and expert judgments $[1,5,9]$, etc. Generally, the objective of WSPS is to select the optimal weapon portfolio form all the candidate weapon systems with regard to its basic capabilities, integrated operational capabilities and technical effects under the available capital and resources conditions [9]. Therefore, just like some other decision-making problem in real-world, including supplier selection [13], resource allocation [13], manufacturing technology selection [14] and project selection [15], WSPS requires a multi-objective decision analysis (MODA). There are many literatures correlated with the multi-objective weapon portfolio selection problem in defense industry. Greiner [12] (2003), Deviren [4] (2009) and Jaewook [11] (2010) studied the selection problem for the weapon projects based on the multiple attribute (objective) decision making method.

As a mathematical programming method, MODA involves multiple objective functions (may be independent or competing objectives) and some constraints [11].For the multi-objective problem, the popular method is to carry out the value or utility analysis and use multi-objective optimization algorithm to obtain the Pareto set. The military application of Portfolio Decision Analysis (PDA) often uses value instead of utility as the measure of the weapon system or project portfolio $[4,5,6,7,8,9]$; Especially in WSPS problem, the definition of value is determined by the decision objectives and the measured criteria. Additionally, these

\footnotetext{
*Corresponding author e-mail: douyajie_nudt@163.com
} 
value assessments, especially in weapon system portfolio selection (WSPS), are more challenging, because of, 1) safety reasons, as it is often difficult to test military systems (e.g., weapon of mass destruction) and, therefore, to ascertain their value in realistic operational conditions $[2,3], 2)$ the possible interactions and independencies among the weapon system, which influence the final value assessment of the portfolio and 3) the uncertainty of the sample datasets for assessment and the target integrated portfolio value. Therefore, with regard to WSPS, it is necessary to carry out a sound, evidence-based value analysis and take full advantage of the available criteria and data in the multi-objective decision process.

For the value analysis of weapon systems, multi-criteria assessment is used mostly with various important criteria to select out the high-capability, technical weapon system portfolio at acceptable cost. With regard to the interactions and independencies in a single portfolio, Jussi and Juuso et al. [9] identified the value of a weapon system portfolio through combat simulation to estimate interdependencies. Liesiö, J. [16] carried out robust portfolio modeling (RPM) methodology with incomplete cost information and project interdependencies; João. C. L. [17] addressed a synergy between the costs and /or the benefits of two projects and constructed the corresponding cost and benefits computation models. Finally, for the uncertain target-value of the dataset samples processing, some related methods accounting for uncertainty can be applied in this study.

Based on the Grey System theory, the grey target (GT) was proposed by Deng [18] to deal with the decision problems with partially known and partially unknown information, also called as "grey" information [19]. When dealing with limited data information, GT has been widely used in various fields and performed excellently $[19,20]$. GT is applied in this study for weapon system portfolio value analysis because of its feasibility. GT is found by the comparison between the target system and the referenced system. Since most weapon systems with interactions and independencies relationship originated from the candidate single weapon system for reference, which makes it possible for the application of GT.

Under the conditions of criteria with target-value, principal component analysis (PCA) is employed in the present study with utility functions to determine the relative value of the weapon system portfolio. In contrast with GT, the weights obtained from PCA are derived from actual data [21,22], and target-value is assigned to criteria that have more information. Based on the value analysis of the weapon system portfolio, we seek to propose a hybrid multi-objective programming algorithms based the weapon system portfolio value analysis through GT and PCA for WSPS problem. First, the multi-objective programming models are built form two perspectives: weapon system portfolio without the interactions and independencies and weapon system portfolio with the interactions and independencies. The former model is defined as MOP1 (multiple objective programming) and the later one is MOP2.Finally, three hybrid algorithms, including GT-MOP1, GT-MOP2 and PCA-MOP2, are proposed for four conditions which are given as follows:

-portfolio without the independencies or target value -portfolio with the independencies but without target value

-portfolio with the independencies and target value

-Portfolio in an incomplete sample data set with the independencies and target value.

The rest of the paper is organized as follows: Section 2 presents the WSPS problem and the weapon system synergy effects. Hybrid algorithms, including GT-MOP1, GT-MOP2 and PCA-MOP2, are given in Section 3 and non-dominated portfolios are generated as by sorting algorithm as a set of Pareto-optimal solutions. Numerical experiments are given under four scenarios to illustrate the feasibilities and advantages of the three hybrid algorithms in Section 4. Conclusions and future work are drawn in Section 5.

\section{Problem Demonstrations}

\subsection{Notations}

In this paper, weapon system portfolio selection is only concern with a set $S=\left\{s_{t}, t=1, \ldots, h\right\}$ of $n$ weapon systems that are worth funding and developing. Formally, a weapon system portfolio is denoted as a subset $P_{j}$ of candidate weapon systems set $S$ that holds the following conditions:

$$
P_{j} \subseteq S
$$

where $j$ is the number of all the possible portfolio $P^{*}=$ $\left\{P_{j}, j=1, \ldots, 2^{h}-1\right\}$ comprised of the candidate weapon system. Theoretically [10], the index $j=2^{h}-1$.

Typically, the overall cost of the portfolio $C\left(P_{j}\right)$ can be estimated by the weapon system acquisition cost per unit. The overall cost computation of the portfolio can be considered as under the assumption that the component systems have the same amounts in a portfolio. A weapon system portfolio can be considered as a feasible one only if it meets with the available capital and resources constraints. The set of feasible portfolio $P_{F}^{*} \subseteq P^{*}$ is

$$
P_{F}^{*}=\left\{P_{j} \in P^{*} \mid C\left(P_{j}\right) \leq B\right\}
$$

where $B$ represents the available capital and resources. The value of a weapon system portfolio is obtained from the multiple criteria assessment model, we assume that there are $\mathrm{m}$ value criteria such that the value of the portfolio $P_{j}$ with regard to the $V_{u}\left(P_{j}\right) \in R, u=1, \ldots, l$. The full set of value along with regard to the corresponding value criteria can be denoted as the vector $V=\left[V_{1}\left(P_{j}\right), \ldots, V_{m}\left(P_{j}\right)\right] \in$ $R^{l}$. All the value criteria are also measured by lots of subcriteria. 
Definition $1\left[\mathbf{1 0 , 1 6 ]}\right.$. Let $P_{j}, P_{j^{\prime}} \in P_{F}^{*}$, portfolio $P_{j}$ dominates $P_{j^{\prime}}$, denoted by $P_{j} \succ P_{j^{\prime}}$, if, and only if, $V_{u}\left(P_{j}\right) \geq V_{u}\left(P_{j^{\prime}}\right)$ and $\left.C_{(} P_{j}\right) \leq C\left(P_{j^{\prime}}\right)$, for all $u=1, \ldots, l$.

Definition 2 [10,16]. A feasible $P_{j} \in P_{F}^{*}$ is a Non-dominated portfolio if, and only if, $P_{j^{\prime}} \in P_{F}^{*}$ does not exist, such that $P_{j^{\prime}} \succ P_{j}$.

The generation of a single Non-dominated weapon system portfolio is easily realized through maximizing the value criteria of the system portfolio, subject to the given cost constraints. Because of the need for multi-objective, the computation of Non-dominated portfolios is often performed by finding all Pareto-optimal solutions of a multi-objective integer programming problem. In which case, the $l+1$ objective integer-programming model [10] is formulated as follows:

$$
\underset{P_{j} \in P_{F}^{*}}{v-\max }\left[V_{1}\left(P_{j}, \ldots, V_{u}\left(P_{j}\right), \ldots, V_{l}\left(P_{j}\right),-C\left(P_{j}\right)\right]\right.
$$

So a portfolio $P_{j} \in P_{F}^{*}$ is Non-dominated if, and only if, another portfolio, $P_{j^{\prime}} \in P_{F}^{*}$ does not exist, such that:

$$
\begin{aligned}
& {\left[V_{1}\left(P_{j^{\prime}}\right), \ldots, V_{u}\left(P_{j^{\prime}}, \ldots, V_{l}\left(P_{j^{\prime}}\right),-C\left(P_{j^{\prime}}\right)\right]\right.} \\
& \supsetneqq\left[V_{1}\left(P_{j}\right), \ldots, V_{u}\left(P_{j}\right), \ldots, V_{l}\left(P_{j}\right),-C\left(P_{j}\right)\right]
\end{aligned}
$$

where the relationship $\supsetneqq$ between two vectors is consistent with the dominance structure given by Definition 1 and Definition 2. Eq. (4) can be used to ascertain the Non-dominated portfolio through pairwise comparisons between any pair of weapon system portfolios.

\subsection{Weapon system independencies}

To account for the interactions and independencies among weapon systems, a synergy concept $[16,17]$ is introduced in this study. For the two or more weapon systems, the synergistic effect on the overall cost of a portfolio is treated as a discount adding to the sum all of the component weapon systems cost, and the synergistic effect on the portfolio value is integrating the separate weapon system value into a synergy one. The various synergies illustrate the different pattern of the interactions and independencies among weapon systems. The principles of synergy in a weapon system portfolio can be described as the following models:

\section{Maximization Synergy Model (MASM)}

The final synergy value of any two or more weapon systems is determined by the maximal criteria value of all the weapon system.

II. Minimization Synergy Model (MISM)

The final synergy value of any two or more weapon systems is determined by the minimal criteria value of all the weapon system.
III. Discount Synergy Model (DSM)

The final synergy value of any two or more weapon systems is determined by the sum of all the criteria value with a discount.

\section{The Proposed Hybrid Multi-objective Programming algorithms with Grey Target and PCA}

\subsection{Grey Target}

The fundamentals of GT are introduced as following [18, 19, 20].

Step 1: Translation of all indices into data patterns;

Suppose that $w_{i}$ is a series with multi-polarized indices and $k$ represents the index mark.

$$
\begin{aligned}
& w_{i}=\left(w_{i}(1), w_{i}(2), \ldots, w_{i}(n)\right), \\
& \forall w_{i}(k) \in w_{i} \Rightarrow k \in K=\{1,2, \ldots, n\}, i \in I=\{1,2, \ldots, m\}
\end{aligned}
$$

Step 2: Construction of the standard system;

Suppose that $P O L(\max ), P O L(\min ), P O L($ mem $)$ represent the maximum, minimum and the average polar respectively, which means that

$$
w_{0}(k)=\max _{i} w_{i}(k), w_{i}(k) \in w(k)
$$

when $\operatorname{POL}(w(k))=P O L(\max )$;

$$
w_{0}(k)=\min _{i} w_{i}(k), w_{i}(k) \in w(k)
$$

when $P O L(w(k))=P O L(\min )$;

$$
w_{0}(k)=\underset{i}{\operatorname{avg}}\left(w_{i}(k), w_{i}(k) \in w(k)\right)
$$

when $\operatorname{POL}(w(k))=\operatorname{POL}($ mem $)$.

Thus, $w_{0}=\left(w_{0}(1), w_{0}(2), \ldots, w_{0}(n)\right)$ is the standard system, which is also called as the "best system".

Step 3: Transformation of grey target;

Carry out the grey target transformation, $T$, so that $T w_{i}(k)=x_{i}(k)$. One typical grey target transformation is denoted as following:

$$
T w_{i}(k)=x_{i}(k)=\frac{\min \left\{w_{i}(k), w_{0}(k)\right\}}{\max \left\{w_{i}(k), w_{0}(k)\right\}}
$$

Step 4: Construction of grey correlation differentiation information space; 


$$
\begin{aligned}
& \Delta_{G R}=\left(\Delta, \xi, \Delta_{0 i},(\max ), \Delta_{0 i},(\min )\right. \\
& \Delta=\left(\Delta_{0 i}(k) \mid i \in I=\{1,2, \ldots, m\}\right. \\
& k \in K=\{1,2, \ldots, n\} \\
& \Delta_{0 i}(k)=\left|x_{0}(k)-x_{i}(k)\right|=\left|1-x_{i}(k)\right|, \\
& \left.x_{0}(k) \in x_{0} \Rightarrow x_{0}=T w_{0}\right) \\
& \xi=0.5 \\
& \Delta_{0 i}(\max )=\max _{i} \max _{k} \Delta_{0 i}(k)=\max _{i} \max _{k}\left|1-x_{i}(k)\right|, \\
& \Delta_{0 i}(\min )=\min _{i} \min _{k} \Delta_{0 i}(k)=\min _{i} \min _{k}\left|1-x_{i}(k)\right|
\end{aligned}
$$

Suppose that $\Delta_{G R}$ is the grey correlation differentiation information space on $@_{G R F \text {. }}$

Step 5: Calculation of center target coefficient and the grey target degree. Center target coefficient denoted as $\gamma\left(x_{0}(k), x_{i}(k)\right)$ is given follows:

$$
\gamma\left(x_{i}(0), x_{i}(k)\right)=\frac{\min _{i} \min _{k} \Delta_{0 i}(0, k)+\xi \max _{i} \max _{k} \Delta_{0 i}(0, k)}{\Delta_{0 i}(0, k)+\xi \max _{i} \max _{k} \Delta_{0 i}(0, k)}
$$

The grey target degree $\gamma\left(x_{0}, x_{i}\right)$ can be formulated as:

$$
\gamma\left(x_{0}, x_{i}\right)=\frac{1}{n} \sum_{k=1}^{n} \gamma\left(x_{0}(k), x_{i}(k)\right)
$$

Step 6: Calculation of the grey target contribution degree.

The contribution coefficient of the index $k$ in the point $i$ can be derived from grey correlation coefficient $\gamma\left(x_{i}(0), x_{i}(k)\right)$ as follows:

$$
\gamma\left(x_{i}(0), x_{i}(k)\right)=\frac{\min _{i} \min _{k} \Delta_{i}(0, k)+\xi \max _{i} \max _{k} \Delta_{i}(0, k)}{\Delta_{i}(0, k)+\xi \max _{i} \max _{k} \Delta_{i}(0, k)}
$$

$\gamma(x(0), x(k))$ is the contribution of index $k$ denoted as:

$$
\gamma(x(0), x(k))=\frac{1}{m} \sum_{i=1}^{m} \gamma\left(x_{i}(0), x_{i}(k)\right)
$$

\subsection{PCA}

As a widely used statistical analysis technique, principal component analysis (PCA) method accounts for selecting the most valuable features or patterns from multivariate data set in order to simplify complex problems [21,22]. A popular application of PCA technique in computer science area is data preprocessing, and especially dimensionality reduction which aims at extracting essential features to preserve most of the original information. A typical PCA process can be described as follows [21]:

We assume that a data matrix $X$ consists of all of the data in training testing sets, when it is put in PCA model, several principal components can be exported as the eigenvectors of the correlation matrix. Formally, the formulation of the correlation matrix $R$ is given as below:

$$
R=E\left[X X^{T}\right]=\frac{1}{N} X X^{T}
$$

where $N$ indicates the samples number in data matrix $X$. Then, the eigen problem $R_{q}=\lambda_{q}$ is settled, $q$ represents the eigenvectors of $R$ while $\lambda_{q}$ indicates its eigenvalue. Lots of eigenvalues for $R$ can be expressed by $\lambda_{e}$ for $e$ from 1 to $v$. Besides, each eigenvector $q_{e}$ is correlated with an eigenvalue $\lambda_{e}$.

Consequently, the projection a of a matrix $\mathrm{Y}$ on the principal direction can be calculated by the transformation function denoted as $T=\left[q_{1}, q_{2}, \ldots, q_{v}\right]$ in the following [22]:

$$
\begin{aligned}
a & =\left[a_{1}, a_{2}, \ldots, a_{v}\right]^{T} \\
& =\left[Y^{T} q_{1}, Y^{T} q_{2}, \ldots, Y^{T} q_{v}\right]^{T} \\
& =T^{T} Y
\end{aligned}
$$

where $a_{e}$ indicates the projection of $Y$ on that principal direction. Therefore, a transformation function $T$ is obtained by PCA from the original data matrix $X$, which is afterwards used in another coordinate system in calculating the projection a with the same data matrix [21].

By means of the PCA process, projection a are ranked in descending order according to the principal directions. The first principal component contribution is larger than $90 \%$, which eigenvalues are employed in this study to represent the weights of the criteria.

\subsection{Hybrid GT-MOP1 algorithm}

Hybrid GT-MOP1 algorithm aims at solving the WSPS problem when Weapon system portfolio is without the interactions and independencies and the criteria target-value is unknown. The algorithm process can be described as follows:

Step 1: Calculate all the contribution of criteria $k$ $\gamma(x(0), x(k))$ by GT method through the single weapon system data sample;

Step 2: Similarity, carry out the Transformation of grey target and calculate all the weights of criteria by GT method;

Step 3: Calculate the entire possible weapon system portfolio $V_{u}\left(P_{j}\right)$ with weighted additive average model for $u=1, \ldots, l, j=1, \ldots, 2^{h}-1$.

Step 4: Calculate the overall cost of the entire possible weapon system portfolio $C_{u}\left(P_{j}\right)$ for $j=1, \ldots, 2^{h}-1$

Step 5: Perform the multiple objective programming model without system synergy or cost discount.

$$
\underset{P_{j} \in P_{F}^{*}}{v-\max _{1}}\left[V_{1}\left(P_{j}\right), \ldots, V_{u}\left(P_{j}\right), \ldots, V_{l}\left(P_{j}\right),-C\left(P_{j}\right)\right]
$$




\subsection{Hybrid GT-MOP2 algorithm}

Hybrid GT-MOP2 algorithm aims at solving the WSPS problem when Weapon system portfolio is with the interactions and independencies and the criteria target-value is unknown. The algorithm process can be described as follows:

Step 1 and Step 2 are similar to Hybrid GT-MOP1 algorithm, however, the samples data are increased with system synergy and cost synergy data, MASM, MISM and DSM are employed to generate the original synergy samples data;

Step 3: Calculate the entire possible weapon system portfolio $V_{u}\left(P_{j}\right)$ with MASM and MISM model for $u=1, \ldots, l, j=1, \ldots, 2^{h}-1$.

Step 4: Calculate the overall cost of the entire possible weapon system portfolio $C_{u}\left(P_{j}\right)$ with DSM for $j=1, \ldots, 2^{h}-1$.

Step 5: Perform the multi-objective programming model with system synergy or cost discount.

$$
\underset{P_{j} \in P_{F}^{*}}{v-\max _{1}}\left[V_{1}\left(P_{j}\right), \ldots, V_{u}\left(P_{j}\right), \ldots, V_{l}\left(P_{j}\right),-C\left(P_{j}\right)\right]
$$

\subsection{Hybrid PCA-MOP2 algorithm}

Hybrid PCA-MOP2 algorithm aims at solving the WSPS problem when Weapon system portfolio is with the interactions and independencies and the criteria target-value is known. The algorithm process can be described as follows:

Step 1: Calculate several principal components through the eigenvectors of the correlation matrix by PCA method (the samples data are increased with system synergy and cost synergy data, MASM, MISM and DSM are employed to generate the original synergy samples data);

Step 2: According the principal component contribution, select the proper eigenvalues to indicate the weights of the criteria;

Step 3: Calculate the criteria value with the target-value and value function;

Step 4: Calculate the entire possible weapon system portfolio $V_{u}\left(P_{j}\right)$ with MASM and MISM model for $u=1, \ldots, l, j=1, \ldots, 2^{h}-1$.

Step 5: Calculate the overall cost of the entire possible weapon system portfolio $C_{u}\left(P_{j}\right)$ with DSM for $j=1, \ldots, 2^{h}-1$.

Step 6: Perform the multiple objective programming model with system synergy or cost discount.

$$
\underset{P_{j} \in P_{F}^{*}}{\nu-\max _{1}}\left[V_{1}\left(P_{j}\right), \ldots, V_{u}\left(P_{j}\right), \ldots, V_{l}\left(P_{j}\right),-C\left(P_{j}\right)\right]
$$

\subsection{Algorithm for generation of Non-dominated portfolios}

However, the pairwise comparisons will exponentially increase and computation becomes time-consuming when the number of feasible system portfolios is large. A sorting strategy, with regard to cost, presented by Kung [24] and Deb [23] has proven to be efficient in identifying the Pareto-optimal solutions from vast amounts of feasible options [10]. The algorithm is given as follows, based on sorting strategy to construct a Non-dominated portfolio set [10]:

Step 1: Assume that the number of the feasible portfolios in $P_{F}^{*}$ is $M, M \leq p \in N^{+}$. The feasible portfolio sorted in descending order with regard to cost is enumerated as $P_{F}^{*}=$ $\left\{P_{1}, P_{2}, \ldots, P_{M}\right\}$, which holds that $C\left(P_{j}\right) \geq C\left(P_{j^{\prime}}\right)$ if $j<j^{\prime}$.

Step 2: The initialization of the Non-dominated portfolios set, $j$. $P_{N D \leftarrow \phi}^{* 0}$ and $j \leftarrow 0$.

Step 3: The iterations are carried out through all the portfolios $P_{j} \in P_{F}^{*}$ in an increasing order of index $j$.

While $j<M$,

(a)The index s increases to $j+1$.

(b)If $\exists P_{s^{\prime}} \in P_{N D}^{* s-1}$ such that $P_{j^{\prime}} \succ P_{j}$ then set $P_{N P}^{* j} \leftarrow P_{N P}^{* j-1}$ and go to step 3.

(c)Set $P_{N D}^{* j} \leftarrow\left\{P_{j}\right\} \cup\left\{P_{j^{\prime}} \in P_{N D}^{* j-1} \mid P_{j} \nsucc P_{j^{\prime}}\right\}$ and go to Step 3.

Step 4: Set $P_{N D}^{*} \leftarrow P_{N D}^{* M} . P_{N D}^{*}$ is the final set of Non-dominated portfolios.

\section{Numerical Experiment and Results}

\subsection{Scenarios description and input data}

To illustrate the procedures involved in the proposed three hybrid algorithms, GT-MOP1, GT-MOP2 and PCA-MOP2, we present a numerical experiment on Air-defense systems portfolio selection. As shown in Fig. 1, ten candidate systems are considered and evaluated based on three criteria and 16 sub criteria. Each sub criterion, identified and structured in the previous stage, has its own characteristic data about the candidate weapon system and relative synergies. The criteria and characteristic data were identified and studied by Ahn [25] and Jaewook [11] as shown in the following Fig. 1.

The candidate weapon systems indexed by $i=1,2, \ldots, 10$ are denoted as a set:

$$
S^{*}=\left\{S_{1}, S_{2}, S_{3}, S_{4}, S_{5}, S_{6}, S_{7}, S_{8}, S_{9}, S_{10}\right\}
$$

There are six systems in the former research and we add some new data to the original one. Other four system data $\left(S_{7}, S_{8}, S_{9}\right.$ and $\left.S_{10}\right)$ is arbitrary and Synergies Data has been generated by MASM, MISM and DSM model (see 
Table. 1, 2 and 3). As shown in Tables 2 and 3, the cost is given in thousands of dollars (e.g. \$1000). However, they are enough meaningful and reasonable to illustrate these algorithms.

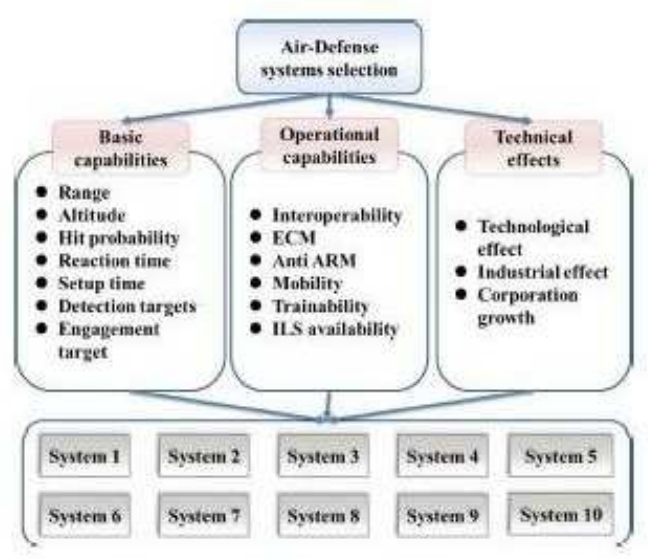

Fig. 1: Hierarchical structure for Air-Defense systems selection

Four scenarios which are tested by the three algorithms are given as follows:

-Scenario 1

Air-defense systems portfolio is without the interactions and independencies and the criteria target value is unknown

-Scenario 2

Air-defense systems portfolio is with the interactions and independencies and the criteria target value is unknown

-Scenario 3

Air-defense systems portfolio is with the interactions and independencies and the criteria target-value is known, the target values can be given as shown in Table. 4 which is adopted form the data tested by Jaewook [11].

-Scenario 4

Air-defense systems portfolio is with the interactions and independencies and the criteria target value is known but the sample data set is incomplete.

\subsection{Results analysis and discussion}

The values of $\mathrm{BC}, \mathrm{OC}$ and $\mathrm{TE}$ distribution with increase of cost under scenario 1, are shown in Figure 2, respectively. On the whole, the value of $\mathrm{BC}, \mathrm{OC}$ and $\mathrm{TE}$ range from $0.4 \sim 1$ and the influence of the increasing cost consumption from $\$ 950,000$ to $\$ 1250,000$ by the improvement of $\mathrm{BC}, \mathrm{OC}$ and $\mathrm{TE}$ is inconspicuous. Most of the overall costs of Non-dominated portfolios (about $85 \%$ ) lie between $\$ 950,000$ and $\$ 1250,000$.

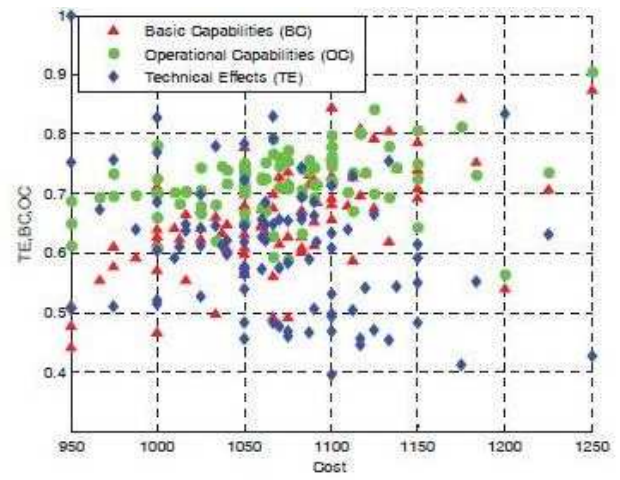

Fig. 2: The value of $\mathrm{BC}, \mathrm{OC}$ and TE distribution with increase of cost under scenario 1 computed by GT-MOP1.

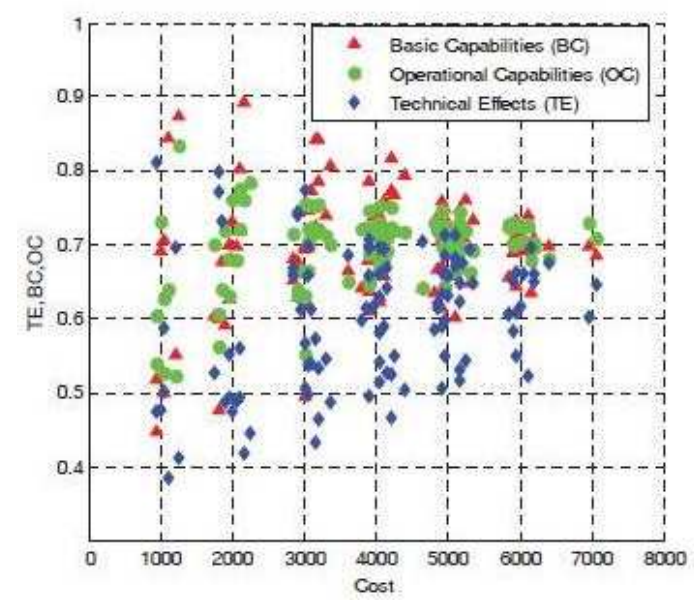

Fig. 3: The value of $\mathrm{BC}, \mathrm{OC}$ and $\mathrm{TE}$ distribution with increase of cost under scenario 2 computed by GT-MOP2.

An obvious convergence can be seen from Figure 3 with regard to values of $\mathrm{BC}, \mathrm{OC}$ and $\mathrm{TE}$ with increasing cost consumption, from $\$ 1000,000$ to $\$ 7000,000$. Therefore, it is easy to see that the interactions and independencies among the component weapon system influence the final portfolio value of $\mathrm{BC}, \mathrm{OC}$ and TE very much, besides, the overall costs of the 106 non-dominated express a discrete assumption distribution.

With the target value and the synergy gained by three synergy model, the value of BC, OC and TE with increase of cost under scenario 3 is generally fluctuant around $2.35,2.45$ and 1.58 , respectively. The PCA-MOP2 algorithm captures the main features of the sample data set.

However, the incomplete data sample has the different performance under scenario 4 in contrast with scenario 3 (see figure 5). The value of basic capability has fluctuated widely between $2 \sim 2.6$ because of the incomplete information related to the sub criteria of basic 
Table 1: Characteristic data on candidate systems and their synergies

\begin{tabular}{|c|c|c|c|c|c|c|c|c|}
\hline \multirow{2}{*}{ Criteria } & \multirow{2}{*}{ Sub-criteria } & \multirow{2}{*}{ Type } & \multicolumn{6}{|c|}{ Candidate System } \\
\hline & & & System 1 & System 2 & System $3 \quad$ S & System 4 & System 5 & System 6 \\
\hline \multirow{7}{*}{$\mathrm{BC}$} & Range & Benefit & 150 & 160 & 135 & 140 & 155 & 170 \\
\hline & Altitude & Benefit & 24 & 28 & 22 & 24 & 28 & 30 \\
\hline & Hit probability & Benefit & 0.75 & 0.8 & 0.75 & 0.75 & 0.8 & 0.8 \\
\hline & Reaction time & Cost & 12 & 9 & 13 & 12 & 10 & 9 \\
\hline & Setup time & Cost & 5.5 & 5 & 6 & 5.5 & 5 & 5 \\
\hline & Detection targets & Benefit & 95 & 110 & 85 & 95 & 100 & 100 \\
\hline & Engagement targets & Benefit & 6 & 9 & 6 & 6 & 8 & 8 \\
\hline \multirow{6}{*}{$\mathrm{OC}$} & Interoperability & Benefit & 0.75 & 0.8 & 0.65 & 0.65 & 0.7 & 0.7 \\
\hline & FCM & Benefit & 0.65 & 0.75 & 0.65 & 0.65 & 0.75 & 0.75 \\
\hline & Anti-ARM & Benefit & 0.75 & 0.8 & 0.65 & 0.7 & 0.7 & 0.8 \\
\hline & Mobility & Benefit & 0.65 & 0.65 & 0.75 & 0.75 & 0.75 & 0.7 \\
\hline & Trainability & Benefit & 0.75 & 0.75 & 0.7 & 0.65 & 0.65 & 0.65 \\
\hline & ILS availability & Benefit & 0.8 & 0.8 & 0.75 & 0.75 & 0.75 & 0.75 \\
\hline \multirow{3}{*}{$\mathrm{TE}$} & Technological effect & Benefit & 0.9 & 0.9 & 1.1 & 1 & 0.9 & 0.9 \\
\hline & Industrial effect & Benefit & 0.8 & 0.8 & 1.2 & 1.1 & 1 & 0.8 \\
\hline & Corporation growth & Benefit & 0.9 & 0.9 & 1.1 & 1 & 1 & 0.8 \\
\hline \multicolumn{9}{|c|}{ Abbreviations Explanation: BC=Basic Capabilities; OC=Operational Capabilities TE= Technical Effects; } \\
\hline System 7 & System 8 & System 9 & System 10 & Synergy $y_{1,4}$ & Synergy $_{1,5}$ & Syn & $\operatorname{rgy}_{1,6} \quad \mathrm{~S}$ & Synergy $_{1,7}$ \\
\hline 165 & 145 & 155 & 160 & 150 & 155 & & 70 & 165 \\
\hline 22 & 26 & 24 & 28 & 24 & 28 & & 30 & 24 \\
\hline 0.7 & 0.75 & 0.7 & 0.8 & 0.75 & 0.8 & & .8 & 0.75 \\
\hline 12 & 9 & 13 & 12 & 12 & 12 & & 12 & 12 \\
\hline 5.5 & 4.5 & 6 & 6.5 & 5.5 & 5.5 & & .5 & 5.5 \\
\hline 90 & 95 & 110 & 100 & 95 & 100 & & 00 & 95 \\
\hline 7 & 8 & 6 & 8 & 6 & 8 & & 8 & 7 \\
\hline 0.7 & 0.8 & 0.65 & 0.6 & 0.7 & 0.73 & & 73 & 0.73 \\
\hline 0.6 & 0.75 & 0.7 & 0.75 & 0.65 & 0.7 & & .7 & 0.63 \\
\hline 0.75 & 0.7 & 0.75 & 0.7 & 0.8 & 0.8 & & 85 & 0.8 \\
\hline 0.75 & 0.7 & 0.65 & 0.7 & 0.8 & 0.8 & & 75 & 0.8 \\
\hline 0.65 & 0.65 & 0.65 & 0.7 & 0.7 & 0.7 & & .7 & 0.7 \\
\hline 0.8 & 0.8 & 0.75 & 0.7 & 0.78 & 0.78 & & .78 & 0.8 \\
\hline 1 & 0.9 & 1.1 & 0.9 & 1.05 & 0.95 & & 95 & 1.05 \\
\hline 0.9 & 1.1 & 1.2 & 1 & 1.15 & 1.05 & & 85 & 0.95 \\
\hline 0.9 & 0.8 & 0.9 & 0.8 & 1.05 & 1.05 & & 95 & 0.95 \\
\hline Synergy $_{1,8}$ & Synergy $_{1,9}$ & Synergy $_{1,10}$ & Synergy $y_{2,4}$ & Synergy $_{2,5}$ & Synergy $_{2,6}$ & Syn & $\mathrm{rgy}_{2,7}$ & Synergy $_{3,4}$ \\
\hline 150 & 155 & 160 & 160 & 160 & 170 & & 65 & 140 \\
\hline 26 & 24 & 28 & 28 & 28 & 30 & & 28 & 24 \\
\hline 0.75 & 0.75 & 0.8 & 0.8 & 0.8 & 0.8 & & .8 & 0.75 \\
\hline 12 & 13 & 12 & 12 & 10 & 9 & & 12 & 13 \\
\hline 5.5 & 6 & 6.5 & 5.5 & 5 & 5 & & .5 & 6 \\
\hline 95 & 110 & 100 & 110 & 110 & 110 & & 10 & 95 \\
\hline 8 & 6 & 8 & 9 & 9 & 9 & & 9 & 6 \\
\hline 0.78 & 0.7 & 0.65 & 0.73 & 0.75 & 0.75 & & 75 & 0.65 \\
\hline 0.7 & 0.68 & 0.7 & 0.7 & 0.75 & 0.75 & & .7 & 0.65 \\
\hline 0.8 & 0.8 & 0.8 & 0.85 & 0.85 & 0.85 & & 85 & 0.75 \\
\hline 0.75 & 0.7 & 0.75 & 0.8 & 0.8 & 0.75 & & .8 & 0.8 \\
\hline 0.7 & 0.7 & 0.73 & 0.7 & 0.7 & 0.7 & & .7 & 0.68 \\
\hline 0.8 & 0.78 & 0.75 & 0.78 & 0.78 & 0.78 & & .8 & 0.75 \\
\hline 0.95 & 1.15 & 0.95 & 1.05 & 0.95 & 0.95 & & 05 & 1.15 \\
\hline 1.15 & 1.25 & 1.05 & 1.15 & 1.05 & 0.85 & & 95 & 1.25 \\
\hline 0.95 & 0.95 & 0.95 & 1.05 & 1.05 & 0.95 & & .95 & 1.15 \\
\hline Synergy $_{3,5}$ & Synergy $_{3,6}$ & Synergy $_{4,5}$ & Synergy $_{4,6}$ & Synergy 7,8 & Synergy $_{1,2,3}$ & Syne & $\operatorname{rgy}_{5,6,7}$ & synergy $8,9,10$ \\
\hline 155 & 170 & 155 & 170 & 165 & 160 & & 70 & 160 \\
\hline 28 & 30 & 28 & 30 & 26 & 28 & & 30 & 28 \\
\hline 0.8 & 0.8 & 0.8 & 0.8 & 0.75 & 0.8 & & 0.8 & 0.8 \\
\hline 13 & 13 & 12 & 12 & 12 & 13 & & 12 & 13 \\
\hline 6 & 6 & 5.5 & 5.5 & 5.5 & 6 & & 5.5 & 6.5 \\
\hline 100 & 100 & 100 & 100 & 95 & 110 & & 00 & 110 \\
\hline 8 & 8 & 8 & 8 & 8 & 9 & & 8 & 8 \\
\hline 0.68 & 0.68 & 0.68 & 0.68 & 0.75 & 0.73 & & .7 & 0.68 \\
\hline 0.7 & 0.7 & 0.7 & 0.7 & 0.7 & 0.68 & & 0.7 & 0.73 \\
\hline 0.75 & 0.85 & 0.75 & 0.85 & 0.8 & 0.85 & & .85 & 0.8 \\
\hline 0.8 & 0.8 & 0.8 & 0.8 & 0.8 & 0.8 & & 0.8 & 0.75 \\
\hline 0.68 & 0.68 & 0.65 & 0.65 & 0.65 & 0.73 & & 65 & 0.67 \\
\hline 0.75 & 0.75 & 0.75 & 0.75 & 0.8 & 0.78 & & .77 & 0.75 \\
\hline 1.15 & 1.15 & 1.05 & 1.05 & 1.05 & 1.15 & & .05 & 1.15 \\
\hline 1.25 & 1.25 & 1.15 & 1.15 & 1.15 & 1.25 & & .05 & 1.15 \\
\hline 1.15 & 1.15 & 1.05 & 1.05 & 0.95 & 1.15 & & .05 & 0.95 \\
\hline
\end{tabular}

Table 2: Cost assumption of candidate systems

\begin{tabular}{ccccccccccc}
\hline & System 1 & System 2 & System 3 & System 4 & System 5 & System 6 & System 7 & System 8 & System 9 & System 10 \\
\hline Cost & 1100 & 1250 & 950 & 1050 & 1050 & 1100 & 950 & 1000 & 1200 & 1150 \\
\hline
\end{tabular}


Table 3: Cost synergies of candidate systems and their discounts

\begin{tabular}{cccccccc}
\hline & Synergy $_{1,4}$ & Synergy $_{1,5}$ & Synergy $_{1,6}$ & Synergy $_{1,7}$ & Synergy $_{1,8}$ & Synergy $_{1,9}$ & Synergy $_{1,10}$ \\
\hline Discount & -200 & -200 & -200 & -200 & -200 & -200 & -200 \\
\hline & Synergy $_{2,4}$ & Synergy $_{2,5}$ & Synergy $_{2,6}$ & Synergy $_{2,7}$ & Synergy $_{3,4}$ & Synergy $_{3,5}$ & Synergy $_{3,6}$ \\
\hline Discount & -200 & -200 & -200 & -200 & -200 & -200 & -200 \\
\hline & Synergy $_{4,5}$ & Synergy $_{4,6}$ & Synergy $_{7,8}$ & Synergy $_{1,2,3}$ & Synergy $_{5,6,7}$ & Synergy & \\
\hline Discount & -200 & -200 & -200 & -450 & -450 & -450 & \\
\hline
\end{tabular}

Table 4: Target values for all the sub-criteria

\begin{tabular}{ccccccccc}
\hline $\begin{array}{c}\text { Sub- } \\
\text { criteria }\end{array}$ & Range & Altitude & $\begin{array}{c}\text { Hit } \\
\text { probability }\end{array}$ & $\begin{array}{c}\text { Reaction } \\
\text { time }\end{array}$ & $\begin{array}{c}\text { Setup } \\
\text { time }\end{array}$ & $\begin{array}{c}\text { Detection } \\
\text { targets }\end{array}$ & $\begin{array}{c}\text { Engagement } \\
\text { targets }\end{array}$ & Interoperability \\
\hline $\begin{array}{c}\text { Target } \\
\text { values }\end{array}$ & 150 & 25 & 0.8 & 10 & 5 & 100 & 8 & 0.7 \\
\hline $\begin{array}{c}\text { Sub- } \\
\text { criteria }\end{array}$ & FCM & $\begin{array}{c}\text { Anti- } \\
\text { ARM }\end{array}$ & Mobility & Trainability & $\begin{array}{c}\text { ILS } \\
\text { availability }\end{array}$ & $\begin{array}{c}\text { Technological } \\
\text { effect }\end{array}$ & $\begin{array}{c}\text { Industrial } \\
\text { effect }\end{array}$ & $\begin{array}{c}\text { Corporation } \\
\text { growth }\end{array}$ \\
\hline $\begin{array}{c}\text { Target } \\
\text { values }\end{array}$ & 0.7 & 0.8 & 0.7 & 0.7 & 0.8 & 1 & 1 & 1 \\
\hline
\end{tabular}

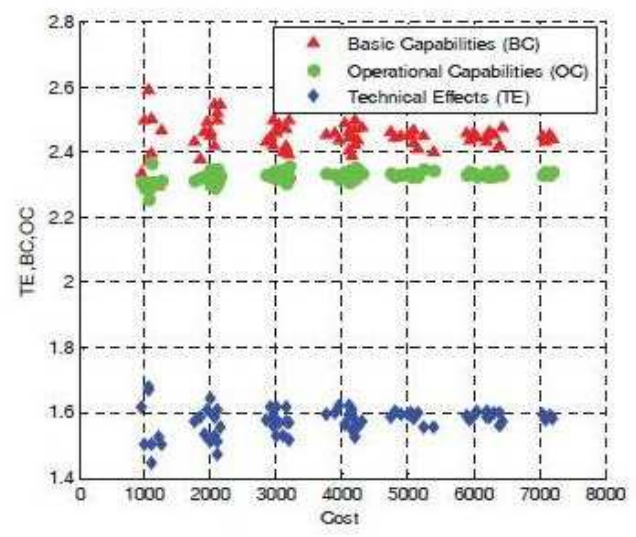

Fig. 4: The value of $\mathrm{BC}, \mathrm{OC}$ and TE distribution with increase of cost under scenario 3 computed by PCA-MOP2.

capability. Contrastively, the value of OC and TE almost unchanged. Therefore, a conclusion can be draw that the PCA-MOP2 algorithm performed excellently with regard to solving the uncertainty of sample data.

Figure 6 shows the relationship among the value of BC, OC and TE of all the Non-dominated weapon system portfolios computed by the proposed three algorithms. As the Figure 6 shown, the results can be clearly divided into two types, the former two has the similar surface because of the application of grey target and the later ones are similar due to the PCA methods. The collective feature of the non-dominated portfolio in the former two scenarios is more obvious than that in the later ones. It means that

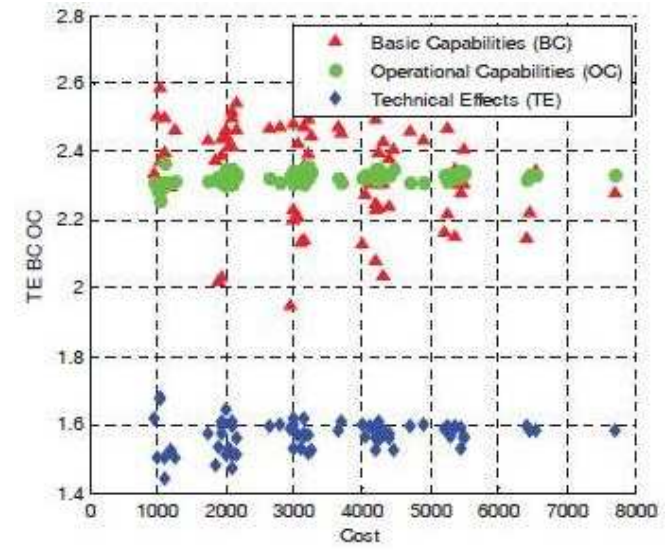

Fig. 5: The value of $\mathrm{BC}, \mathrm{OC}$ and $\mathrm{TE}$ distribution with increase of cost under scenario 4 computed by PCA-MOP2.

more abundant portfolio alternatives will be generated by the PCA-MOP2 algorithm.

Table 5 shows the list the 93 weapon system portfolios computed by GT-MOP1 under scenario 1 . System 3 is prominent with the most high frequency in the 93 non-dominated portfolio when target value is missing under scenario 1(See Table 6), however, it only comes out once in the non-dominated portfolio generated by PCA-MOP2 algorithm with target value under scenario 4. System 5 and System 6 have the similar high frequency under the four scenarios. Therefore, target value has the direct effect on determine whether the system is valuable or not. Furthermore, the weapon system with high quality and excellent performance generally become to be the core system in the non-dominated portfolio. Then, all the system frequency and rate in the Non-dominated portfolios computed by 


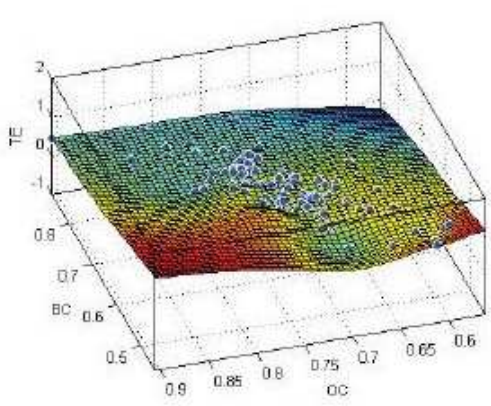

(a): Scenario 1 computed by GI-MOP1

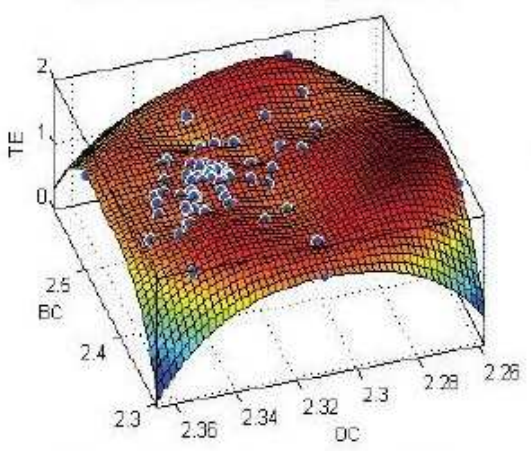

(c): Scenario 3 computed by PCA-MOP1

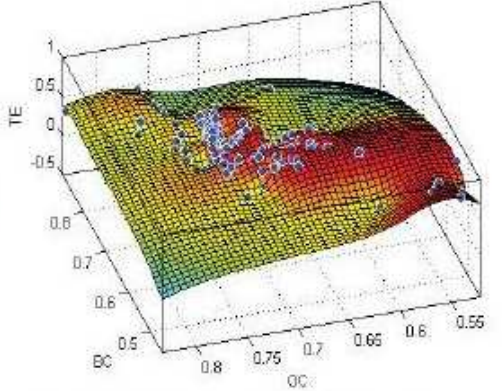

(b): Scenario 2 computed by GT-MOP2

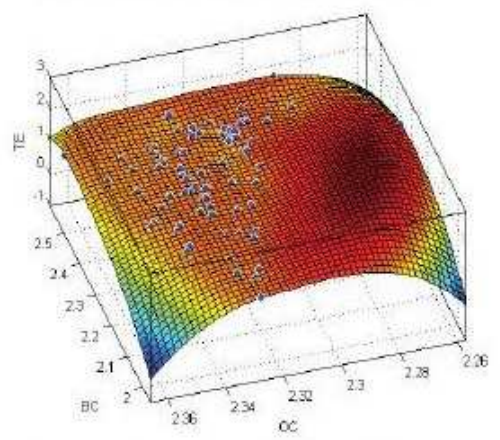

(d): Scenario 4 computed by PCA-MOP2

Fig. 6: The value of $\mathrm{BC}, \mathrm{OC}$ and $\mathrm{TE}$ distribution under four scenarios computed by three algorithms.

Table 5: List of the 93 weapon system portfolios computed by GT-MOP1 under scenario 1

\begin{tabular}{|c|c|c|c|c|c|c|c|}
\hline Portfolio & Systems & Portfolio & Systems & Portfolio & Systems & Portfolio & Systems \\
\hline $\mathrm{P}_{1}$ & $\mathrm{~S}_{9}$ & $\mathrm{P}_{25}$ & $\mathrm{~S}_{3}, \mathrm{~S}_{5}$ & $\mathrm{P}_{49}$ & $\mathrm{~S}_{2}, \mathrm{~S}_{5}, \mathrm{~S}_{8}$ & $\mathrm{P}_{73}$ & $\mathrm{~S}_{2}, \mathrm{~S}_{3}, \mathrm{~S}_{5}, \mathrm{~S}_{8}, \mathrm{~S}_{9}$ \\
\hline $\mathrm{P}_{2}$ & $\mathrm{~S}_{8}$ & $\mathrm{P}_{26}$ & $\mathrm{~S}_{3}, \mathrm{~S}_{5}, \mathrm{~S}_{9}$ & $\mathrm{P}_{50}$ & $\mathrm{~S}_{2}, \mathrm{~S}_{5}, \mathrm{~S}_{6}$ & $\mathrm{P}_{74}$ & $\mathrm{~S}_{2}, \mathrm{~S}_{3}, \mathrm{~S}_{5}, \mathrm{~S}_{7}$ \\
\hline $\mathrm{P}_{3}$ & $\mathrm{~S}_{7}$ & $\mathrm{P}_{27}$ & $\mathrm{~S}_{3}, \mathrm{~S}_{5}, \mathrm{~S}_{8}$ & $\mathrm{P}_{51}$ & $\mathrm{~S}_{2}, \mathrm{~S}_{5}, \mathrm{~S}_{6}, \mathrm{~S}_{8}$ & $\mathrm{P}_{75}$ & $\mathrm{~S}_{2}, \mathrm{~S}_{3}, \mathrm{~S}_{5}, \mathrm{~S}_{7}, \mathrm{~S}_{8}$ \\
\hline $\mathrm{P}_{4}$ & $\mathrm{~S}_{7}, \mathrm{~S}_{8}$ & $\mathrm{P}_{28}$ & $\mathrm{~S}_{3}, \mathrm{~S}_{5}, \mathrm{~S}_{8}, \mathrm{~S}_{9}$ & $\mathrm{P}_{52}$ & $\mathrm{~S}_{2}, \mathrm{~S}_{5}, \mathrm{~S}_{6}, \mathrm{~S}_{8}$ & $\mathrm{P}_{76}$ & $\mathrm{~S}_{2}, \mathrm{~S}_{3}, \mathrm{~S}_{5}, \mathrm{~S}_{6}$ \\
\hline $\mathrm{P}_{5}$ & $\mathrm{~S}_{6}$ & $\mathrm{P}_{29}$ & $\mathrm{~S}_{3}, \mathrm{~S}_{5}, \mathrm{~S}_{7}, \mathrm{~S}_{8}$ & $\mathrm{P}_{53}$ & $\mathrm{~S}_{2}, \mathrm{~S}_{5}, \mathrm{~S}_{6}, \mathrm{~S}_{8}, \mathrm{~S}_{9}$ & $\mathrm{P}_{77}$ & $\mathrm{~S}_{2}, \mathrm{~S}_{3}, \mathrm{~S}_{5}, \mathrm{~S}_{6}, \mathrm{~S}_{9}$ \\
\hline $\mathrm{P}_{6}$ & $\mathrm{~S}_{6}, \mathrm{~S}_{9}$ & $\mathrm{P}_{30}$ & $\mathrm{~S}_{3}, \mathrm{~S}_{5}, \mathrm{~S}_{6}$ & $\mathrm{P}_{54}$ & $\mathrm{~S}_{2}, \mathrm{~S}_{5}, \mathrm{~S}_{6}, \mathrm{~S}_{7}$ & $\mathrm{P}_{78}$ & $\mathrm{~S}_{2}, \mathrm{~S}_{3}, \mathrm{~S}_{5}, \mathrm{~S}_{6}, \mathrm{~S}_{8}$ \\
\hline $\mathrm{P}_{7}$ & $\mathrm{~S}_{6}, \mathrm{~S}_{8}$ & $\mathrm{P}_{31}$ & $\mathrm{~S}_{3}, \mathrm{~S}_{5}, \mathrm{~S}_{6}, \mathrm{~S}_{8}$ & $\mathrm{P}_{55}$ & $\mathrm{~S}_{2}, \mathrm{~S}_{5}, \mathrm{~S}_{6}, \mathrm{~S}_{7}, \mathrm{~S}_{8}$ & $\mathrm{P}_{79}$ & $\mathrm{~S}_{2}, \mathrm{~S}_{3}, \mathrm{~S}_{5}, \mathrm{~S}_{6}, \mathrm{~S}_{8}, \mathrm{~S}_{9}$ \\
\hline $\mathrm{P}_{8}$ & $\mathrm{~S}_{5}$ & $\mathrm{P}_{32}$ & $\mathrm{~S}_{3}, \mathrm{~S}_{5}, \mathrm{~S}_{6}, \mathrm{~S}_{8}, \mathrm{~S}_{9}$ & $\mathrm{P}_{56}$ & $\mathrm{~S}_{2}, \mathrm{~S}_{4}, \mathrm{~S}_{8}$ & $\mathrm{P}_{80}$ & $\mathrm{~S}_{2}, \mathrm{~S}_{3}, \mathrm{~S}_{5}, \mathrm{~S}_{6}, \mathrm{~S}_{7}$ \\
\hline $\mathrm{P}_{9}$ & $\mathrm{~S}_{5}, \mathrm{~S}_{8}$ & $\mathrm{P}_{33}$ & $\mathrm{~S}_{3}, \mathrm{~S}_{5}, \mathrm{~S}_{6}, \mathrm{~S}_{7}$ & $\mathrm{P}_{57}$ & $\mathrm{~S}_{2}, \mathrm{~S}_{4}, \mathrm{~S}_{6}, \mathrm{~S}_{8}$ & $\mathrm{P}_{81}$ & $\mathrm{~S}_{2}, \mathrm{~S}_{3}, \mathrm{~S}_{5}, \mathrm{~S}_{6}, \mathrm{~S}_{7}, \mathrm{~S}_{8}$ \\
\hline $\mathrm{P}_{10}$ & $\mathrm{~S}_{5}, \mathrm{~S}_{7}, \mathrm{~S}_{8}$ & $\mathrm{P}_{34}$ & $\mathrm{~S}_{3}, \mathrm{~S}_{5}, \mathrm{~S}_{6}, \mathrm{~S}_{7}, \mathrm{~S}_{8}$ & $\mathrm{P}_{58}$ & $\mathrm{~S}_{2}, \mathrm{~S}_{4}, \mathrm{~S}_{5}, \mathrm{~S}_{6}$ & $\mathrm{P}_{82}$ & $\mathrm{~S}_{2}, \mathrm{~S}_{3}, \mathrm{~S}_{4}$ \\
\hline $\mathrm{P}_{11}$ & $\mathrm{~S}_{5}, \mathrm{~S}_{6}$ & $\mathrm{P}_{35}$ & $\mathrm{~S}_{3}, \mathrm{~S}_{4}$ & $\mathrm{P}_{59}$ & $\mathrm{~S}_{2}, \mathrm{~S}_{4}, \mathrm{~S}_{5}, \mathrm{~S}_{6}, \mathrm{~S}_{8}$ & $\mathrm{P}_{83}$ & $\mathrm{~S}_{2}, \mathrm{~S}_{3}, \mathrm{~S}_{4}, \mathrm{~S}_{9}$ \\
\hline $\mathrm{P}_{12}$ & $\mathrm{~S}_{5}, \mathrm{~S}_{6}, \mathrm{~S}_{8}$ & $\mathrm{P}_{36}$ & $\mathrm{~S}_{3}, \mathrm{~S}_{4}, \mathrm{~S}_{9}$ & $\mathrm{P}_{60}$ & $\mathrm{~S}_{2}, \mathrm{~S}_{3}$ & $\mathrm{P}_{84}$ & $\mathrm{~S}_{2}, \mathrm{~S}_{3}, \mathrm{~S}_{4}, \mathrm{~S}_{8}$ \\
\hline $\mathrm{P}_{13}$ & $\mathrm{~S}_{3}$ & $\mathrm{P}_{37}$ & $\mathrm{~S}_{3}, \mathrm{~S}_{4}, \mathrm{~S}_{6}, \mathrm{~S}_{8}$ & $\mathrm{P}_{61}$ & $\mathrm{~S}_{2}, \mathrm{~S}_{3}, \mathrm{~S}_{9}$ & $\mathrm{P}_{85}$ & $\mathrm{~S}_{2}, \mathrm{~S}_{3}, \mathrm{~S}_{4}, \mathrm{~S}_{8}, \mathrm{~S}_{9}$ \\
\hline $\mathrm{P}_{14}$ & $\mathrm{~S}_{3}, \mathrm{~S}_{9}$ & $\mathrm{P}_{38}$ & $\mathrm{~S}_{2}$ & $\mathrm{P}_{62}$ & $\mathrm{~S}_{2}, \mathrm{~S}_{3}, \mathrm{~S}_{8}$ & $\mathrm{P}_{86}$ & $\mathrm{~S}_{2}, \mathrm{~S}_{3}, \mathrm{~S}_{4}, \mathrm{~S}_{7}$ \\
\hline $\mathrm{P}_{15}$ & $\mathrm{~S}_{3}, \mathrm{~S}_{8}$ & $\mathrm{P}_{39}$ & $\mathrm{~S}_{2}, \mathrm{~S}_{9}$ & $\mathrm{P}_{63}$ & $\mathrm{~S}_{2}, \mathrm{~S}_{3}, \mathrm{~S}_{7}$ & $\mathrm{P}_{87}$ & $\mathrm{~S}_{2}, \mathrm{~S}_{3}, \mathrm{~S}_{4}, \mathrm{~S}_{7}, \mathrm{~S}_{8}$ \\
\hline $\mathrm{P}_{16}$ & $\mathrm{~S}_{3}, \mathrm{~S}_{8}, \mathrm{~S}_{9}$ & $\mathrm{P}_{40}$ & $\mathrm{~S}_{2}, \mathrm{~S}_{8}$ & $\mathrm{P}_{64}$ & $\mathrm{~S}_{2}, \mathrm{~S}_{3}, \mathrm{~S}_{7}, \mathrm{~S}_{8}$ & $\mathrm{P}_{88}$ & $\mathrm{~S}_{2}, \mathrm{~S}_{3}, \mathrm{~S}_{4}, \mathrm{~S}_{5}$ \\
\hline $\mathrm{P}_{17}$ & $\mathrm{~S}_{3}, \mathrm{~S}_{7}$ & $\mathrm{P}_{41}$ & $\mathrm{~S}_{2}, \mathrm{~S}_{8}, \mathrm{~S}_{9}$ & $\mathrm{P}_{65}$ & $\mathrm{~S}_{2}, \mathrm{~S}_{3}, \mathrm{~S}_{7}, \mathrm{~S}_{8}, \mathrm{~S}_{9}$ & $\mathrm{P}_{89}$ & $\mathrm{~S}_{2}, \mathrm{~S}_{3}, \mathrm{~S}_{4}, \mathrm{~S}_{5}, \mathrm{~S}_{8}$ \\
\hline $\mathrm{P}_{18}$ & $\mathrm{~S}_{3}, \mathrm{~S}_{7}, \mathrm{~S}_{9}$ & $\mathrm{P}_{42}$ & $\mathrm{~S}_{2}, \mathrm{~S}_{7}, \mathrm{~S}_{8}$ & $\mathrm{P}_{66}$ & $\mathrm{~S}_{2}, \mathrm{~S}_{3}, \mathrm{~S}_{6}$ & $\mathrm{P}_{90}$ & $\mathrm{~S}_{2}, \mathrm{~S}_{3}, \mathrm{~S}_{4}, \mathrm{~S}_{5}, \mathrm{~S}_{8}, \mathrm{~S}_{9}$ \\
\hline $\mathrm{P}_{19}$ & $\mathrm{~S}_{3}, \mathrm{~S}_{7}, \mathrm{~S}_{8}$ & $\mathrm{P}_{43}$ & $\mathrm{~S}_{2}, \mathrm{~S}_{6}$ & $\mathrm{P}_{67}$ & $\mathrm{~S}_{2}, \mathrm{~S}_{3}, \mathrm{~S}_{6}, \mathrm{~S}_{9}$ & $\mathrm{P}_{91}$ & $\mathrm{~S}_{2}, \mathrm{~S}_{3}, \mathrm{~S}_{4}, \mathrm{~S}_{5}, \mathrm{~S}_{6}, \mathrm{~S}_{7}, \mathrm{~S}_{8}$ \\
\hline $\mathrm{P}_{20}$ & $\mathrm{~S}_{3}, \mathrm{~S}_{6}$ & $\mathrm{P}_{44}$ & $\mathrm{~S}_{2}, \mathrm{~S}_{6}, \mathrm{~S}_{9}$ & $\mathrm{P}_{68}$ & $\mathrm{~S}_{2}, \mathrm{~S}_{3}, \mathrm{~S}_{6}, \mathrm{~S}_{8}$ & $\mathrm{P}_{92}$ & $\mathrm{~S}_{1}, \mathrm{~S}_{3}, \mathrm{~S}_{8}$ \\
\hline $\mathrm{P}_{21}$ & $\mathrm{~S}_{3}, \mathrm{~S}_{6}, \mathrm{~S}_{9}$ & $\mathrm{P}_{45}$ & $\mathrm{~S}_{2}, \mathrm{~S}_{6}, \mathrm{~S}_{8}$ & $\mathrm{P}_{69}$ & $\mathrm{~S}_{2}, \mathrm{~S}_{3}, \mathrm{~S}_{6}, \mathrm{~S}_{8}, \mathrm{~S}_{9}$ & $\mathrm{P}_{93}$ & $\mathrm{~S}_{1}, \mathrm{~S}_{2}, \mathrm{~S}_{8}$ \\
\hline $\mathrm{P}_{22}$ & $\mathrm{~S}_{3}, \mathrm{~S}_{6}, \mathrm{~S}_{8}$ & $\mathrm{P}_{46}$ & $\mathrm{~S}_{2}, \mathrm{~S}_{6}, \mathrm{~S}_{8}, \mathrm{~S}_{9}$ & $\mathrm{P}_{70}$ & $\mathrm{~S}_{2}, \mathrm{~S}_{3}, \mathrm{~S}_{6}, \mathrm{~S}_{7}, \mathrm{~S}_{8}$ & & \\
\hline $\mathrm{P}_{23}$ & $\mathrm{~S}_{3}, \mathrm{~S}_{6}, \mathrm{~S}_{8}, \mathrm{~S}_{9}$ & $\mathrm{P}_{47}$ & $\mathrm{~S}_{2}, \mathrm{~S}_{6}, \mathrm{~S}_{7}, \mathrm{~S}_{8}$ & $\mathrm{P}_{71}$ & $\mathrm{~S}_{2}, \mathrm{~S}_{3}, \mathrm{~S}_{5}$ & & \\
\hline $\mathrm{P}_{24}$ & $\mathrm{~S}_{3}, \mathrm{~S}_{6}, \mathrm{~S}_{7}, \mathrm{~S}_{8}$ & $\mathrm{P}_{48}$ & $\mathrm{~S}_{2}, \mathrm{~S}_{5}$ & $\mathrm{P}_{72}$ & $\mathrm{~S}_{2}, \mathrm{~S}_{3}, \mathrm{~S}_{5}, \mathrm{~S}_{8}$ & & \\
\hline
\end{tabular}

GT-MOP2 and PCA-MOP2 under other three scenarios are given in Table 7, Table 8 and Table 9. 
Table 6: The system frequency and rate in the 93 Non-dominated portfolios computed by GT-MOP1

\begin{tabular}{ccccccccccc}
\hline System & 1 & 2 & 3 & 4 & 5 & 6 & 7 & 8 & 9 & 10 \\
\hline Frequency & 2 & 55 & 58 & 17 & 40 & 42 & 25 & 52 & 27 & 0 \\
Rate & $2.15 \%$ & $59.14 \%$ & $62.37 \%$ & $18.28 \%$ & $43.01 \%$ & $45.16 \%$ & $26.89 \%$ & $55.91 \%$ & $29.03 \%$ & 0 \\
\hline
\end{tabular}

Table 7: The system frequency and rate in the 106 Non-dominated portfolios computed by GT-MOP2

\begin{tabular}{ccccccccccc}
\hline System & 1 & 2 & 3 & 4 & 5 & 6 & 7 & 8 & 9 & 10 \\
\hline Frequency & 32 & 80 & 63 & 53 & 55 & 56 & 30 & 41 & 14 & 0 \\
Rate & $30.19 \%$ & $75.47 \%$ & $59.43 \%$ & $50 \%$ & $51.89 \%$ & $52.83 \%$ & $28.30 \%$ & $38.68 \%$ & $13.21 \%$ & 0 \\
\hline
\end{tabular}

Table 8: The system frequency and rate in the 71 Non-dominated portfolios computed by PCA-MOP2 with complete samples

\begin{tabular}{ccccccccccc}
\hline System & 1 & 2 & 3 & 4 & 5 & 6 & 7 & 8 & 9 & 10 \\
\hline Frequency & 53 & 21 & 0 & 14 & 48 & 38 & 36 & 30 & 19 & 9 \\
Rate & $74.65 \%$ & $29.58 \%$ & 0 & $19.72 \%$ & $67.61 \%$ & $53.52 \%$ & $50.70 \%$ & $42.25 \%$ & $26.76 \%$ & $12.68 \%$ \\
\hline
\end{tabular}

Table 9: The system frequency and rate in the 73 Non-dominated portfolios computed by PCA-MOP2 with incomplete samples

\begin{tabular}{ccccccccccc}
\hline System & 1 & 2 & 3 & 4 & 5 & 6 & 7 & 8 & 9 & 10 \\
\hline Frequency & 45 & 25 & 1 & 33 & 40 & 40 & 10 & 20 & 25 & 6 \\
Rate & $61.64 \%$ & $34.25 \%$ & $1.37 \%$ & $45.21 \%$ & $54.79 \%$ & $54.79 \%$ & $13.70 \%$ & $27.40 \%$ & $34.25 \%$ & $8.22 \%$ \\
\hline
\end{tabular}

\section{Conclusion}

In this paper, Weapon Systems Portfolio Selection (WSPS) can be considered as a multi-objective decision analysis (MODA) problem. For the multi-objective problem, the popular method is to carry out the value or utility analysis and use multi-objective optimization algorithm to obtain the Pareto set. Because of the challenging features of WSPS, Grey Target (GT) and principal component analysis (PCA) method are employed in this study to solving the value analysis of weapon system portfolio with system interaction and independencies value under small data set sample conditions. WSPS problem are simplified into four scenarios: portfolio without the independencies or target value, portfolio with the independencies but without target value, portfolio with the independencies and target value and portfolio in an incomplete sample data with the independencies and with target value. Three hybrid algorithms, GT-MOP1, GT-MOP2 and PCA-MOP2 are proposed to solving the problems in contrast with each other. Numerical experiments are given in Section 4 illustrate the feasibilities and advantages of the three hybrid algorithms under four scenarios.

\section{Acknowledgement}

This work was supported by the National Natural Science Foundation of China: Reasoning and Learning Approach to Evidential Network with Application under Grant nos. 71201168 and Hunan Provincial Innovation Foundation for Postgraduate under Grant nos.CX2013B023.

\section{References}

[1] D. Buede, T. Bresnick, Applications of decision analysis to the military systems acquisition process, Interfaces, 22, 110125 (1992).

[2] R. Burk, G. Parnell, Portfolio decision analysis-lessons from military applications, In: A. Salo, J. Keisler, A. Morton, Portfolio Decision Analysis: Improved Methods for Resource Allocation. New York: Springer, 333-334 (2011).

[3] R. Burk, G. Parnell, Portfolio decision analysis-lessons from military applications. In: A. Salo, J. Keisler, A. Morton, Portfolio Decision Analysis: Improved Methods for Resource Allocation. New York: Springer, 335-336 (2011).

[4] M. D. Deviren, S. Yavuz, and N. Kılınç, Weapon selection using the AHP and TOPSIS methods under fuzzy environment, Expert Systems with Applications, 36, 81438151 (2009).

[5] M. J. Sullivan, Best practices: An integrated portfolio management approach to weapon system investments could improve DOD's acquisition outcomes, United States Government Accountability Office, Washington, D.C., Rep. GAO-07-388, (2007).

[6] S. Parnell, B. Gimeno, D. Westphal, J. Engelbrecht, R .Szafranski, Multiple perspective R\&D portfolio analysis for the National Reconnaissance Office's technology enterprise, Military Operations Research, 6, 19-34 (2001).

[7] S. Parnell, G. Bennett, J. Engelbrecht, R. Szafranski, Improving customer support resource allocation within the National Reconnaissance Office, Interfaces, 32, 77-90 (2002).

[8] S. Parnell, C. Burk, A. Schulman, D. Westphal, L. Kwan, J. Blackhurst, P. Verret, H. Karasopoulos, Air Force Research Laboratory space technology value model: creating capabilities for future customers, Military Operations Research, 9, 5-18 (2004). 
[9] L. Buckshaw, S. Parnell, L. Unkenholz, L. Parks, M. Wallner, S. Saydjari. Mission oriented risk and design analysis of critical information systems, Military Operations Research, 10, 19-38 (2005).

[10] J. Kangaspunta, J. Liesiö, P. Mild, A. Salo, Cost-efficiency analysis of weapon system portfolios, European Journal of Operational Research, 223, 264-275 (2012).

[11] J. Lee, S.-H. Kang, J. Rosenberger, and S. B. Kim, A hybrid approach of goal programming for weapon systems selection, Computers \& Industrial Engineering, 58, 521-527 (2010).

[12] M. A. Greiner, J. W. Fowler, D. L. Shunk, W. M. Carlyle, and R. T. McNutt, A hybrid approach using the analytic hierarchy process and integer programming to screen weapon systems projects, IEEE Transactions On Engineering Management, 50, 192-203 (2003).

[13] Z. Li, W. Wong, C. Kwong, An Integrated Model of Material Supplier Selection and Order Allocation Using Fuzzy Extended AHP and Multi-objective Programming, Mathematical Problems in Engineering, 2013, Article ID 363718, 14 pages (2012).

[14] J. C. Mankins, Technology readiness levels, A White Paper, NASA, Washington, DC, (1995).

[15] M. Rafiee and F. Kianfar, A scenario tree approach to multi-period project selection problem using real-option valuation method, The International Journal of Advanced Manufacturing Technology, 56, 411-420 (2011).

[16] J. Liesiö, P. Mild, A. Salo, Robust portfolio modeling with incomplete cost information and project interdependencies, European Journal of Operational Research, 190, 679-695 (2008).

[17] C. L. Joõo, M. Alec, A. B. C. Carlo, PROBE-A multicriteria decision support system for portfolio robustness evaluation, Decision support systems, 54, 534-550 (2012).

[18] J. L. Deng, Theory of grey systems, Wuhan, Hubei: Huazhong University of Science and Technology Press, (1990).

[19] E. Kayacan, B. Ulutas, O. Kaynak, Grey system theorybased models in time series prediction, Expert Systems with Applications, 37, 1784-1789 (2010).

[20] Z. J. Xie, Y. C. Bao, R. Q. Xie, F. S. Peng, Grey quantitative method about the affection degree of tactics and technology performance indices to the effectiveness of weapon systems, Systems Engineering and Electronics, 27, 1924-1926 (2005).

[21] I. T. Jolliffe, Principal Component Analysis, second ed, Springer, Berlin, (2002).

[22] H. Abdi, L. J. Williams, Principal component analysis, Wiley Interdisciplinary Reviews: Computational Statistics, 2, 433-459 (2010).

[23] K. Deb, Multi-Objective Optimization Using Evolutionary Algorithms. John Wiley \& Sons, Chichester, (2001).

[24] H. Kung, F. Luccio, F. Preparata, On finding the maxima of a set of vectors, Journal of the Association for Computing Machinery, 22, 469-476 (1975).

[25] C. W. Ahn, A study on the determining missile system by using integer goal programming and AHP, Korea National Defense University, (2003).

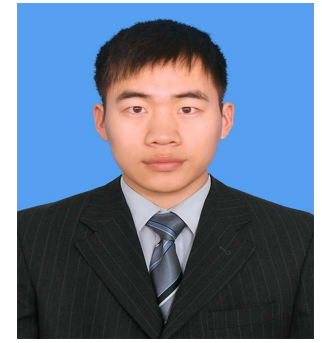

Yajie Dou received the M.Sc. degree in engineering from the National University of Defense Technology (NUDT), Changsha, P. R.China, in 2011. $\mathrm{He}$ is pursuing the $\mathrm{Ph} . \mathrm{D}$. degree in the School of Information System and Management Science at NUDT. His main research interests include weapon system portfolio decision and effectiveness evaluation.

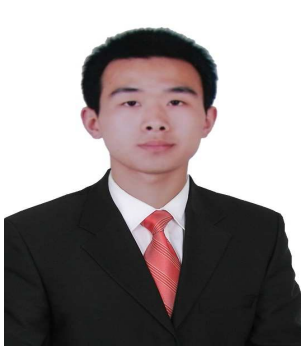

Pengle Zhang received the B.Sc. degree in Management from NUDT in 2013.He is currently a Master candidate in the School of Information System and Management Science at NUDT. His main research interests include system of systems requirement planning, and effectiveness evaluation.

Jiang Jiang received the

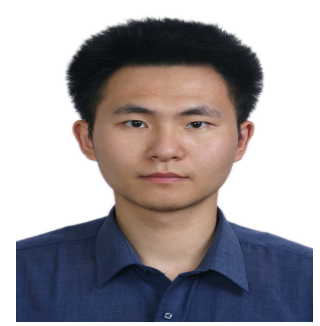
B.Sc. degree and M.Sc. degree in system engineering from NUDT, PRC in 2004 and 2006, respectively. $\mathrm{He}$ is currently a lecture in School of Information System and Management, NUDT. His research interests include multiple criteria decision making and risk analysis.

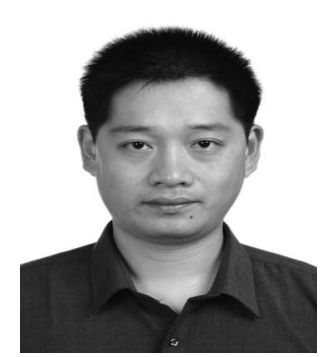

modeling.

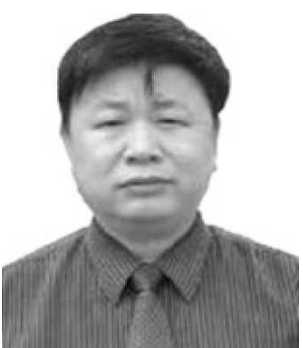

Kewei Yang received the Ph.D. degree in Management from NUDT in 2004. $\mathrm{He}$ is an Associate Professor at the College of Information System and Management in NUDT. His research interests focus on Intelligent Agent Simulation, Defense Acquisition and System of Systems requirement

Yingwu Chen received the M.Sc. degree in system engineering, and the Ph.D. degree in engineering from NUDT in 1987 and 1994, respectively. $\mathrm{He}$ is a Professor in NUDT. His current research interests include assistant decision making systems for planning, decision-making systems for project evaluation, management decisions and system of systems engineering. 